\title{
Estudo de inclusões fluidas do Granito Parapente, Gaspar (SC): implicações para a evolução tectônica da Zona de Cisalhamento Itajaí-Perimbó
}

\author{
Ingrid Weber HADLICH${ }^{1}$, Fernando Jacques ALTHOFF², Luiz Henrique RONCHI ${ }^{3}$ \& Michel \\ DUBOIS $^{4}$
}

1 Programa de Pós-graduação em Geociências, Instituto de Geociências, Universidade Federal do Rio Grande do Sul. Av. Bento Gonçalves, 9.500, CEP 91.540-000, Porto Alegre, RS, Brasil (ingrid.hadlich@gmail.com).

2 Departamento de Geociências, Universidade Federal de Santa Catarina. Campus Reitor João David Ferreira Lima, s/n, Trindade, CEP 88040-900, Florianópolis, SC, Brasil (althoff@cfh.ufsc.br).

3 Centro de Engenharias, Curso de Engenharia Geológica, Universidade Federal de Pelotas. Campi Pelotas, Praça Domingos Rodrigues, no 2, CEP 96010-440, Pelotas, RS, Brasil (lhronchi@hotmail.com).

4 Laboratoire de Génie Civil et géo-Environnement (LGCgE, EA 4515), Université Lille1. Bâtiment SN5, 59655, Villeneuve D’Ascq CEDEX, França (michel.dubois@univ-lille1.fr).

Recebido em 11/2016. Aceito para publicação em 11/2017.

Versão online publicada em 16/3/2018 (www.pesquisasemgeociencias.ufrgs.br)

\begin{abstract}
Resumo - Ao colocar rochas do Complexo Metamórfico Brusque em contato com rochas da Bacia do Itajaí, a Zona de Cisalhamento Itajaí-Perimbó assinala o limite entre os domínios central e externo do Cinturão Dom Feliciano no Escudo Catarinense. A evolução desta estrutura de escala crustal pode ser investigada por meio do estudo do Granito Parapente, que aflora no Município de Gaspar em meio à zona de cisalhamento. Com idade de cristalização de $843 \mathrm{Ma}$, este granito tipo A é um excelente marcador de deformação relacionada ao funcionamento da zona de cisalhamento. Para estimar condições de temperatura, pressão e profundidade relacionadas à deformação foram analisadas inclusões fluidas em três tipos de quartzo do Granito Parapente. As temperaturas mínimas de aprisionamento e as pressões e profundidades médias obtidas pelas inclusões fluidas são as seguintes: $220-190^{\circ} \mathrm{C}, 6 \mathrm{kbar}$ e $\sim 23 \mathrm{~km}$, para o quartzo I, da fácies menos deformada do granito, considerado mais antigo; $160-130^{\circ} \mathrm{C}, 4 \mathrm{kbar}$ e $14 \mathrm{~km}$, para o quartzo II, de filonito, formado em etapa mais recente da evolução da zona de cisalhamento; e $260-220^{\circ} \mathrm{C}, 190-170^{\circ} \mathrm{C},<12 \mathrm{~km} \mathrm{e}<3 \mathrm{kbar}$ para o quartzo III, de veio que corta a foliação da zona de cisalhamento. A variação de profundidade evidenciada para a formação dos quartzos I e II atesta que a zona de cisalhamento funcionou inicialmente como cavalgamento, alçando o Granito Parapente em cerca de $10 \mathrm{~km}$ em níveis crustais intermediários. Nos três tipos de quartzo foram observadas inclusões com fluidos aquosos com salinidades baixas, o que evidencia que a Zona de Cisalhamento Itajaí-Perimbó foi conduto para fluidos durante um longo período.
\end{abstract}

Palavras-chave: Cinturão Dom Feliciano, geotectônica, filonito.

\begin{abstract}
Fluid inclusions Study on the Parapente Granite, Gaspar (SC): implications to THE TeCtonic eVolution of the Itajaí-Perimbó Shear Zone. By placing the Brusque Metamorphic Complex rocks in contact with the Itajaí Basin rocks, the Itajaí-Perimbó Shear Zone delimits the boundary between the Central and Outer areas of the Dom Feliciano belt in the Santa Catarina Shield. The evolution of this crustal scale structure can be investigated by the study of the Parapente granite, which outcrops in the city of Gaspar, through the shear zone. The crystallization age of 843 Ma makes this type A granite an excellent strain marker related to the operation of the shear zone. To estimate temperature, pressure and depth conditions strain related, there were analyzed fluid inclusions in three quartz types from the Parapente granite. The minimum trapping temperatures and the mean pressures and depths obtained by fluid inclusions are: $220-190^{\circ} \mathrm{C}, 6 \mathrm{kbar}$ and $23 \mathrm{~km}$, for quartz I, from the less deformed granite facies, considered earlier; $160-130^{\circ} \mathrm{C}, 4 \mathrm{kbar}$ and 14 $\mathrm{km}$, for quartz II, from the phyllonite, formed in the most recent stage of the shear zone evolution; and $260-220^{\circ} \mathrm{C}, 190-170^{\circ} \mathrm{C},<12 \mathrm{~km}$ and $<3 \mathrm{kbar}$, for the quartz III, from a vein that cuts the shear zone foliation. The variation in depth evidenced by the formation of quartz I and II shows that the shear zone operated initially as a thrust fault, rising in almost $10 \mathrm{~km}$ the Parapente granite in intermediate crustal levels. All the three quartz types present low salinities fluid inclusions, showing that the Itajaí-Perimbó Shear Zone was duct for fluids over a long period.
\end{abstract}

Keywords: Dom Feliciano belt, geotectonic, phyllonite. 


\section{Introdução}

A Zona de Cisalhamento Itajaí-Perimbó (ZCIP) marca no Escudo Catarinense o limite entre os domínios externo e central do Cinturão Dom Feliciano. 0 domínio externo é formado pela Bacia do Itajaí e o interno essencialmente pelo Complexo Metamórfico Brusque. Mapas e perfis com algum detalhe mostram que entre estas duas unidades encontram-se rochas mais antigas ao longo da zona de cisalhamento, como é o caso das rochas graníticas deformadas da Faixa Ribeirão da Prata (Biondi et al., 1992; Rostirolla et al., 1992). Mais para leste, no município de Gaspar, a ZCIP aloja o Granito Parapente, o qual tem sido associado aos primeiros episódios da história do Cinturão Dom Feliciano (Basei et al., 2008; Brito Neves \& Fuck, 2013).

Entre as rochas de falha do Granito Parapente ocorrem milonitos, cataclasitos e filonitos (Ronchi, 2014; Ronchi \& Althoff, 2015). Filonitos são rochas de falha hidratadas que comumente se formam a partir de cataclasitos, onde a passagem de fluidos é facilitada (Schmid \& Handy, 1991; Jefferies et al., 2006). A existência de filonitos no Granito Parapente sugere que a ZCIP foi um conduto importante de fluidos crustais, conforme modelos bem estabelecidos (Vrolijk 1987; Hodgkins \& Stewart, 1994).

A aplicação da análise de inclusões fluidas a estudos estruturais e tectônicos iniciou na década de 1990 (p.e. Parry \& Bruhn, 1987; Foreman \& Dunne, 1991; Hodgkins \& Stewart, 1994; Parry, 1998; Boullier, 1999) e hoje se encontra bastante difundida (p.e. Szulc et al., 2008; Lacroix et al., 2011, 2014; Passelègue et al., 2014).

São apresentados os resultados do estudo de inclusões fluidas em grãos de quartzo de rochas de falha do Granito Parapente e de microveios que o cortam. $\mathrm{O}$ objetivo do trabalho foi estabelecer condições de temperatura e pressão (profundidades) que pudessem ser relacionadas à evolução da ZCIP, nos domínios do Granito Parapente.

\section{2 Área, materiais e métodos}

\subsection{Geologia}

A ZCIP (Silva, 1991) ainda não foi alvo de estudos específicos. As informações disponíveis encontram-se em textos que tratam da geologia do Complexo Metamórfico Brusque (Philipp et al., 2004), da Bacia do Itajaí (Rostirolla et al., 1992; Caldasso et al., 1995; Basei et al., 2011b), ou da mi- neralização sulfetada de Ribeirão da Prata (Biondi et al., 1992; Rostirolla et al., 1999). Esta zona de cisalhamento tem orientação NE-SW (Fig. 1) e se estende por mais de $60 \mathrm{~km}$ no Escudo Catarinense (Silva, op. cit.). Em superfície ela é marcada por uma foliação de alto ângulo, observada em xistos do Complexo Metamórfico Brusque (Philipp et al., op. cit.) e no Granito Parapente, com direção média em torno de N60E e mergulhos de 70 a $80^{\circ}$ para NW ou SE (Ronchi \& Althoff, 2015).

Em sua evolução, a ZCIP teve dois movimentos principais. Inicialmente foi um cavalgamento, com transporte para NW, e posteriormente passou a ter movimentos direcionais (Biondi et al., 1992; Rostirolla et al., 1992; Philipp et al., 2004; Ronchi \& Althoff, 2015). Estruturas associadas à movimentação direcional também são observadas em rochas das formações Rio Bonito, Serra Alta e Teresina da Bacia do Paraná, o que indica que a zona de cisalhamento esteve ativa pelo menos até o Permiano superior (Rostirolla et al., 2003). 0 cavalgamento posicionou rochas do Complexo Metamórfico Brusque sobre rochas da Bacia do Itajaí, na borda sul da bacia.

Um conjunto de datações disponíveis na literatura permite balizar a evolução da ZCIP. A mineralização na Faixa Ribeirão da Prata, alojada em meio à ZCIP e considerada pós-tectônica (Biondi et al., 1992), tem idade de $\sim 534 \mathrm{Ma}$, indicada pela assinatura isotópica do $\mathrm{Pb}$ da galena no minério (Rocha et al., 2005). A deposição e deformação da Bacia do Itajaí ocorreram entre $563 \pm 3$ Ma (zircões detríticos em arenito) e $549 \pm 4$ Ma (zircões de riolito) (Guadagnin et al., 2010). A fase principal de deformação e metamorfismo regional de fácies xisto verde no Complexo Metamórfico Brusque é estimada entre 640 e 600 Ma (Basei et al., 2011a). 0 Granito Parapente, exposto em meio à ZCIP (Fig. 1), tem idade de cristalização de $843 \pm 12 \mathrm{Ma}(\mathrm{U}-\mathrm{Pb}$ em zircões - SHRIMP; Basei et al., 2008). Com características de granito tipo A, o Granito Parapente pode ser relacionado ao ambiente tectônico distensivo em que se formou a bacia sedimentar que originou o Complexo Metamórfico Brusque (Basei et al., 2008).

O Granito Parapente possui forma alongada, com cerca de $10 \mathrm{~km} \times 1 \mathrm{~km}$, com orientação NE-SW concordante com a orientação da ZCIP. É um sienogranito leucocrático porfirítico, com coloração rósea e granulação média, composto essencialmente por feldspato potássico e quartzo, com plagioclásio subordinado (Basei et al., 2008). Muscovita é o mineral varietal; os minerais acessórios são epidoto, magnetita e zircão, por sua vez clorita e sericita são os minerais de alteração (Basei et al., op. cit.). 
Em escala de afloramento a feição de deformação predominante do Granito Parapente é uma foliação de alto ângulo marcada pela orientação dos grãos de muscovita. Em escala microscópica, o Granito Parapente apresenta deformação frágildúctil a frágil, o que manifesta seu caráter pré-tectônico em relação à ZCIP (Ronchi \& Althoff, 2015). As rochas de falha são essencialmente milonitos e filonitos que ocorrem em bandas com espessuras de $40 \mathrm{~cm}$ a $2 \mathrm{~m}$, além de cataclasitos que têm ocorrência restrita, em meio a bandas miloníticas. Os indicadores cinemáticos sugerem que os milonitos se formaram em contexto de cavalgamento e os filonitos em contexto de falhamento direcional. Veios de quartzo leitoso com espessuras centimétricas são comuns no granito e formam pelo menos dois grandes grupos: veios concordantes com a foliação e veios que cortam a foliação do granito (Ronchi \& Althoff, op. cit.).

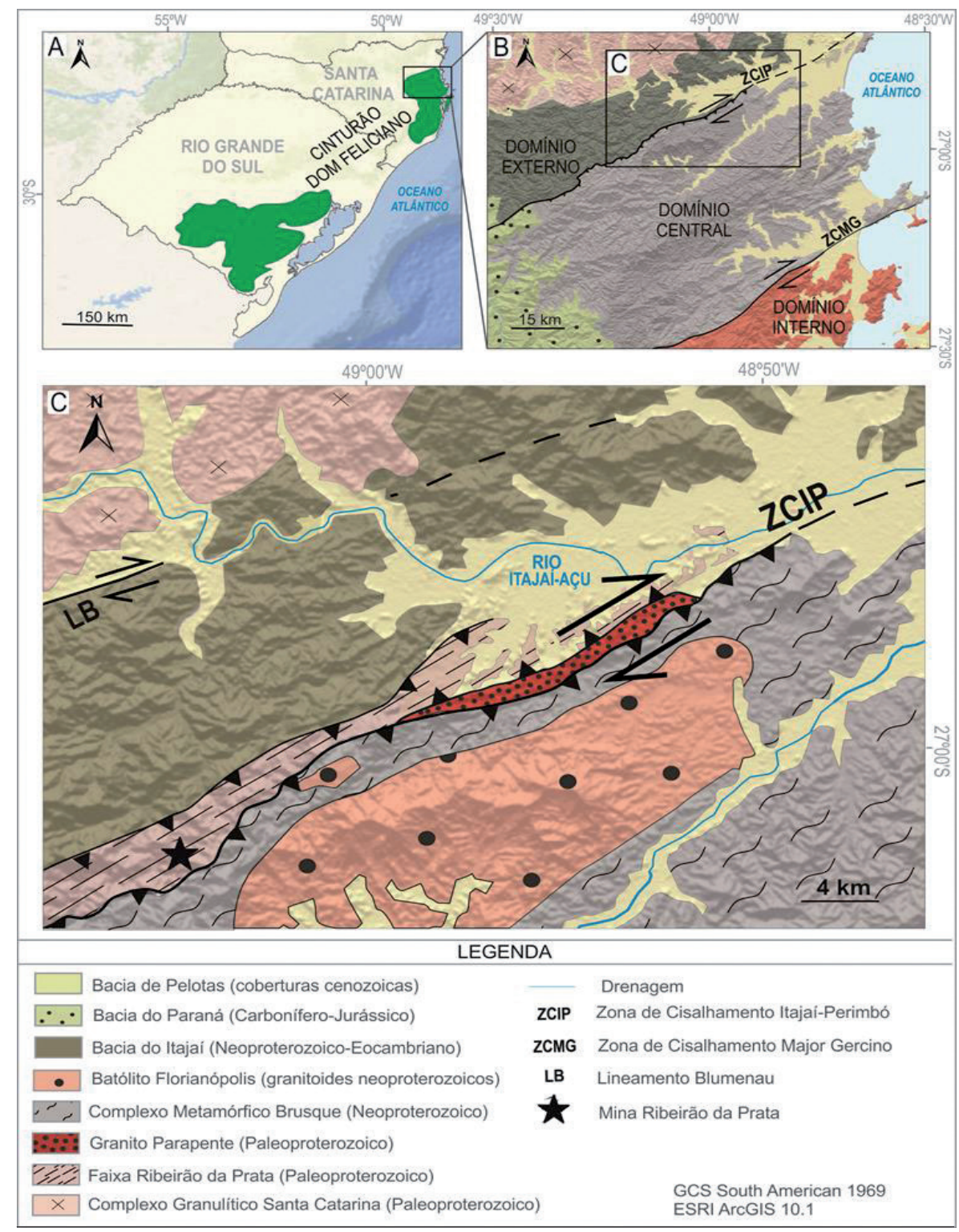

Figura 1. Contexto geológico regional. A) Localização do Cinturão Dom Feliciano no sul do Brasil (adaptada de Chemale Jr., 2007); B) Domínios interno, central e externo do Cinturão Dom Feliciano no Escudo Catarinense e falhas que os delimitam (adaptado de Basei et al., 2011a); C) Geologia da região de Gaspar (com base em Wildner et al., 2014).

Figure 1. Regional geological context. A) Localization of the Dom Feliciano belt in the South of Brazil (adapted from Chemale Jr., 2007); B) Inner, central and outer domains of the Dom Feliciano belt in the Catarinense Shield and faults that delimit them (adapted from Basei et al., 2011a); C) Geology of the Gaspar region (based on Wildner et al., 2014).

\subsection{Amostragem}

O Granito Parapente ainda não está cartografado em detalhe. As amostras utilizadas neste trabalho foram selecionadas com base em dois perfis estruturais transversais ao granito e à ZCIP (Fig. 2), elaborados por Ronchi (2014). Um deles está situado no sopé do Morro do Parapente, ao longo da Rodovia SC-108 (Gaspar - Brusque), e o outro em estrada secundária nas proximidades do $F a$ - 


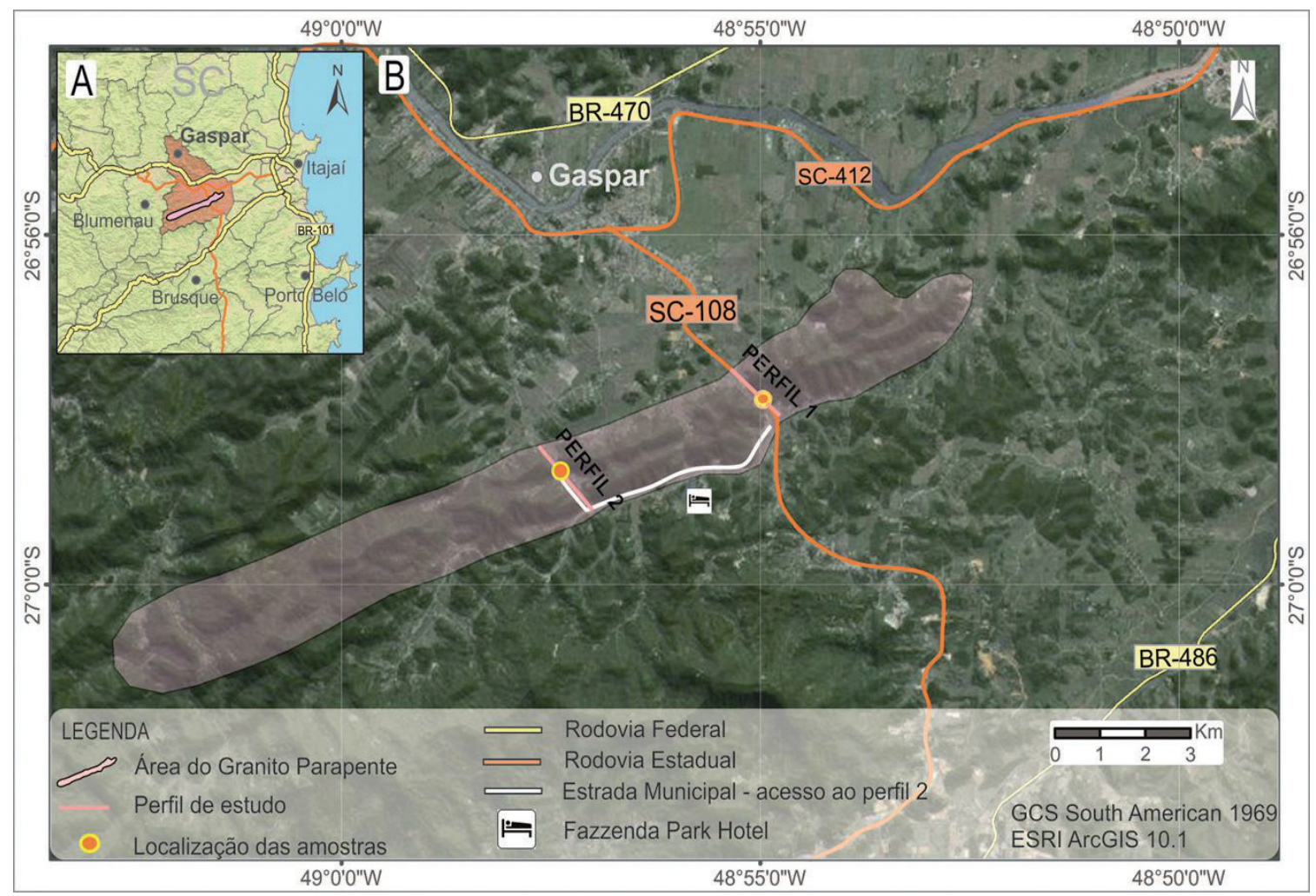

Figura 2. Localização das amostras. A) Localização do Granito Parapente no Município de Gaspar, SC. B) Localização das amostras coletadas no Granito Parapente.

Figure 2. Samples location. A) Location of Parapente granite in the Gaspar city, SC. B) Location of collected samples in the Parapente granite.

zzenda Park Hotel. Foram selecionadas três amostras com grãos de quartzo de gerações diferentes, que abrangem um amplo período da evolução do granito: granito foliado (com menor deformação), com grãos de quartzo mais antigos recristalizados

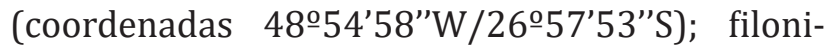
to, com porfiroblastos de quartzo (coordenadas 485' $23^{\prime \prime} \mathrm{W} / 26^{\circ} 58^{\prime} 42^{\prime \prime} \mathrm{S}$ ); e veio de quartzo secante à foliação do granito, com grãos de quartzo mais recentes (mesmas coordenadas do filonito).

\subsection{Métodos}

Dois métodos complementares foram utilizados para a determinação de condições P-T: análise petrográfica-microestrutural e estudo de inclusões fluidas. A análise petrográfica-microestrutural foi realizada no Laboratório de Microscopia Ótica da Universidade Federal de Santa Catarina, em um microscópio petrográfico Meiji Techno ML9400. As rochas de falha foram descritas com base nos critérios de Trouw et al. (2010). Lâminas delgadas e seções bipolidas foram confeccionadas no Laboratório de Análise de Minerais e Rochas - LAMIR, da Universidade Federal do Paraná. A petrografia das inclusões fluidas considerou parâmetros como tamanho, formato, cor, quantidade e tipos de fases e o volume relativo das fases presentes nas inclu- sões fluidas à temperatura ambiente (Hollister \& Crawford, 1981; Roedder, 1984; Fuzikawa, 1985). A seleção de inclusões fluidas para a microtermometria foi realizada de acordo com os critérios de Van den Kerkhof \& Hein (2001). Foram selecionados grupos de inclusões pertencentes a uma mesma geração e evitadas inclusões com vazamento, estiramento e outras deformações.

A análise das inclusões fluidas foi realizada no laboratório do Curso de Engenharia Geológica da Universidade Federal de Pelotas. Foi utilizada uma platina microtermométrica Linkam THMS-G 600, onde as amostras podem ser resfriadas e aquecidas entre $-180^{\circ} \mathrm{C}$ e $600^{\circ} \mathrm{C}$. 0 funcionamento da platina Linkam é explicado por Shepherd (1981). A platina é acoplada a um microscópio biológico de luz transmitida Nikon Eclipse 50i (aumento máximo de 50x/0,60), a um contêiner de nitrogênio líquido (Linkam LNP 95) e a um registrador/controlador de temperaturas (Linkam T-95).

A temperatura mínima de aprisionamento para inclusões fluidas aquosas foi definida pela temperatura de homogeneização $\left(\mathrm{T}_{\mathrm{h}}\right)$ das fases presentes nas inclusões. Após o congelamento dos fluidos foi medida a temperatura do ponto de fusão do último cristal de gelo $\left(\mathrm{T}_{\mathrm{fg}}\right)$ (Roedder, 1984). As medidas de $\mathrm{T}_{\mathrm{h}}$ e $\mathrm{T}_{\mathrm{fg}}$ foram realizadas nas mesmas inclusões, aumentando a confiabilidade do 
trabalho. Em razão do tamanho muito pequeno das inclusões nas amostras analisadas não foi possível observar as temperaturas do eutético $\left(T_{f m}-\right.$ first melting temperature). A salinidade e densidade das inclusões fluidas foram calculadas a partir da temperatura de fusão do gelo e da Equação de Estado de Bodnar (2003).

As isócoras (linhas de mesma densidade), formadas a partir de pares de pressão e temperatura, foram obtidas a partir dos valores médios de salinidade e valores máximos e mínimos de temperatura de homogeneização no software FLINCOR (Brown, 1989). A temperatura mínima de aprisionamento das inclusões fornece a pressão mínima de aprisionamento. Geotermômetros independentes foram empregados para a correção das pressões, obtendo pares P-T mais próximos da realidade para o aprisionamento das inclusões.

0 cálculo da profundidade em que as inclusões fluidas foram aprisionadas foi feito utilizando o gradiente geotérmico obtido pela correlação do maior valor de pressão mínima de aprisionamento das inclusões fluidas com sua respectiva temperatura, conforme o método de Parry \& Bruhn (1987).

\section{Resultados}

\subsection{Petrografia e microestruturas}

\subsubsection{Granito foliado}

As amostras de mão do granito foliado apresentam coloração rósea e foliação incipiente dada pela orientação de bandas de quartzo e muscovita. São visíveis a olho nu porfiroclastos de K-feldspato e, na matriz, quartzo e muscovita. Ao microscópio ótico são observados essencialmente fenocristais de ortoclásio de até $1 \mathrm{~mm}$, em geral bastante pertitizados, com forte extinção ondulante, com o predomínio de grãos fraturados, com fragmentos progressivamente menores à medida em que se distanciam dos porfiroclastos que lhes deram origem. A matriz é composta por estes fragmentos menores de K-feldspato, quartzo recristalizado e muscovita.

O quartzo apresenta todas as feições típicas da deformação plástica: extinção ondulante, subgrãos e novos grãos formados por rotação de subgrãos. Quartzo recristalizado preenche fraturas dos porfiroclastos de K-feldspato (Fig. 3A). Em lâminas paralelas aos eixos X e Z do elipsoide de deformação finita observa-se a presença de ribbons de quartzo (Fig. 3B). Além disso, localmente observa-se recristalização incipiente de K-feldspato (Fig. 3C). A muscovita, quando ocorre, forma bandas paralelas às de quartzo compondo a foliação da rocha. Em pequenas proporções ocorrem epidoto, minerais opacos e possível sericita.

As microestruturas de deformação predominantes no granito foliado são características de deformação essencialmente frágil (feldspato)-dúctil (quartzo). A formação de ribbons de quartzo e a recristalização incipiente em K-feldspato são coerentes com temperaturas de deformação do granito foliado próximas a $500^{\circ} \mathrm{C}$ (Blenkinsop, 2000; Passchier \& Trouw, 2005).

\subsubsection{Filonito}

0 filonito é caracterizado em amostras de mão por porfiroblastos de quartzo e foliação bem desenvolvida formada por muscovita, que confere à rocha uma textura sedosa. Possui coloração rósea ou esverdeada, dependendo da coloração assumida pela mica. Em lâmina delgada observam-se porfiroblastos de quartzo com tamanhos de até 2,0 mm e matriz com quartzo fino, muscovita e mais raramente minerais opacos (Fig. 3D).

Os porfiroblastos de quartzo são ovalados, com o eixo maior paralelo à foliação. Apresentam extinção ondulante, recristalização incipiente e caudas de recristalização. Alguns porfiroblastos apresentam faces retas, paralelas à foliação, formadas por dissolução por pressão (Fig. 3E). As microestruturas associadas aos filonitos sugerem uma deformação com temperatura de até $350^{\circ} \mathrm{C}$ (Blenkinsop, 2000; Passchier \& Trouw, 2005).

\subsubsection{Veio de quartzo}

0 veio de espessura milimétrica que corta a foliação do granito é formado por quartzo leitoso. Ao microscópio ótico observa-se parcialmente textura poligonal - grãos com contatos retos, e leve extinção ondulante (Fig. 3F). Estima-se que a temperatura em que o quartzo do veio se formou é inferior a $300^{\circ} \mathrm{C}$, considerando que o veio corta a foliação do granito, e não possui texturas/estruturas que sugiram temperaturas maiores (Blenkinsop, 2000; Passchier \& Trouw, 2005).

\subsection{Petrografia das inclusões fluidas}

\subsubsection{Quartzo do granito foliado}

As inclusões fluidas do quartzo do granito foliado analisadas na microtermometria apresen- 


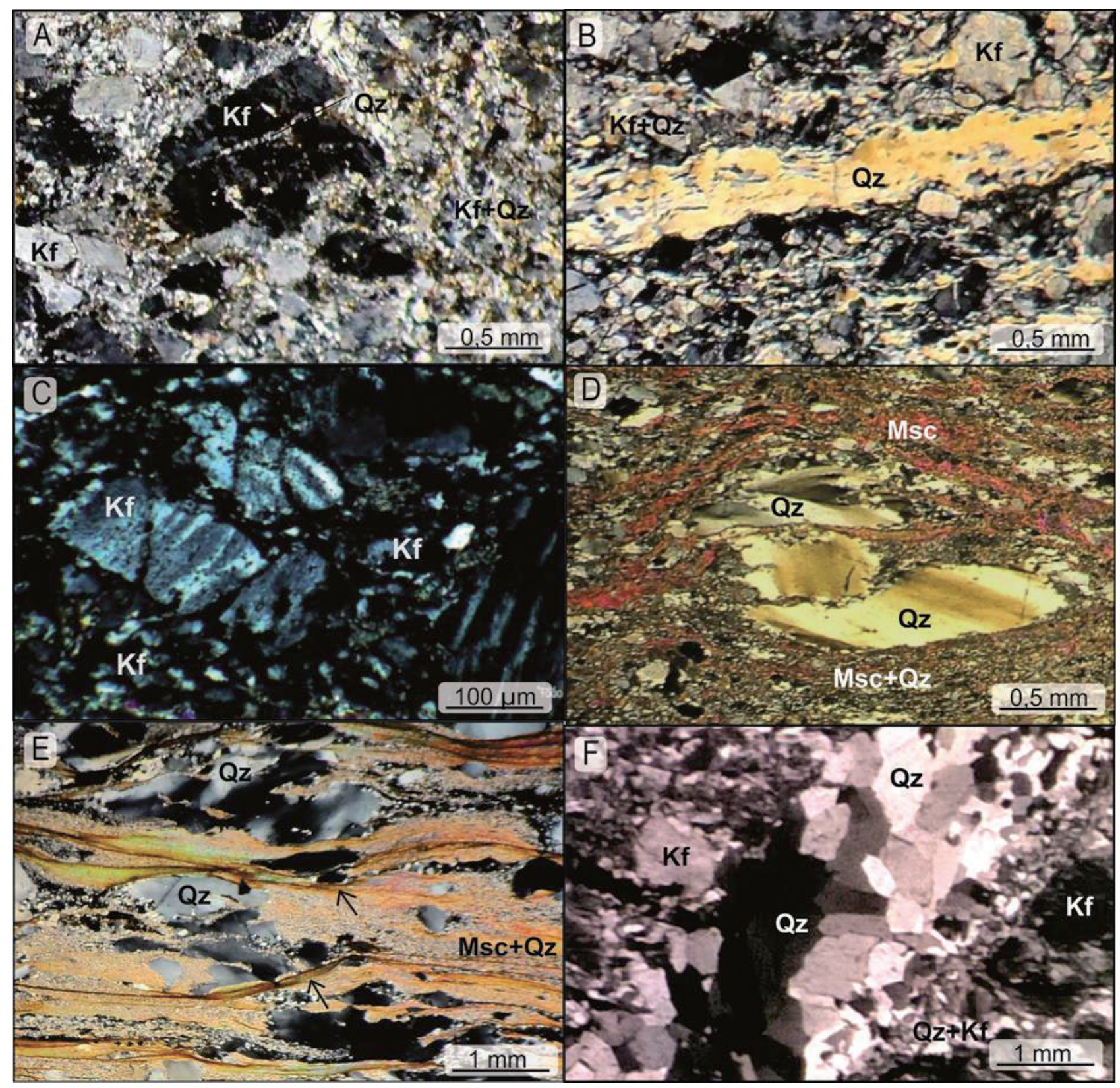

Figura 3. Microestruturas em rochas do Granito Parapente. A) Fraturas no K-feldspato preenchidas por quartzo recristalizado no granito foliado, NX; B) Ribbon de quartzo no granito foliado, NX; C) Recristalização incipiente de K-feldspato no granito foliado, NX; D) Porfiroblastos alongados de quartzo com extinção ondulante, contornados por bandas de muscovita no filonito, NX; E) Evidências de dissolução por pressão nos porfiroblastos de quartzo, indicadas por seta, e caudas de recristalização de quartzo no filonito, NX; F) Cristais de quartzo com textura poligonal em microveio, NX (Qz: quartzo, Kf: K-feldspato, Msc: muscovita). Figure 3. Microstructures on Parapente granite rocks. A) Fractures in K-feldspar filled with recrystallized quartz in foliated granite, NX; B) Quartz ribbon in foliated granite, NX; C) Incipient K-feldspar recrystallization in foliated granite, NX; D) Elongated quartz porphyiroblasts with wavy extinction skirted by muscovite bands in phyllonite, $N X$; E) Evidence of pressure solution in quartz porphyroblasts, indicated by arrow, and quartz recrystallization tail in the phyllonite, NX; F) Quartz crystals with polygonal structure in micro vein, $N X$ (Qz: quartz, Kf: K-feldspar, Msc: muscovite).

tam tamanhos entre 8 e $15 \mu \mathrm{m}$, são claras, aquosas, bifásicas $(\mathrm{L}+\mathrm{V})$, sem indícios de presença de $\mathrm{CO}_{2}$. As inclusões bifásicas estão associadas a inclusões monofásicas aquosas. As inclusões podem indicar os contornos de subgrãos (formados pela deformação) (Fig. 4A e B), ocorrer sem orientação preferencial, ou ainda formar trilhas que podem cortar os subgrãos mas não transpassam a borda do cristal(Fig. 4C, D e E).

$\mathrm{O}$ volume de preenchimento de gás das in- clusões foi calculado entre 8 e $16 \%$. As formas das inclusões variam entre arredondadas, alongadas, anedrais, subedrais e euedrais. A origem destas inclusões pode ser considerada primária, em relação ao quartzo recristalizado devido à deformação (e não ao quartzo magmático, o qual não foi foco deste estudo). As propriedades similares apontam para a existência de uma única assembleia de inclusões fluidas no quartzo recristalizado do granito foliado. 

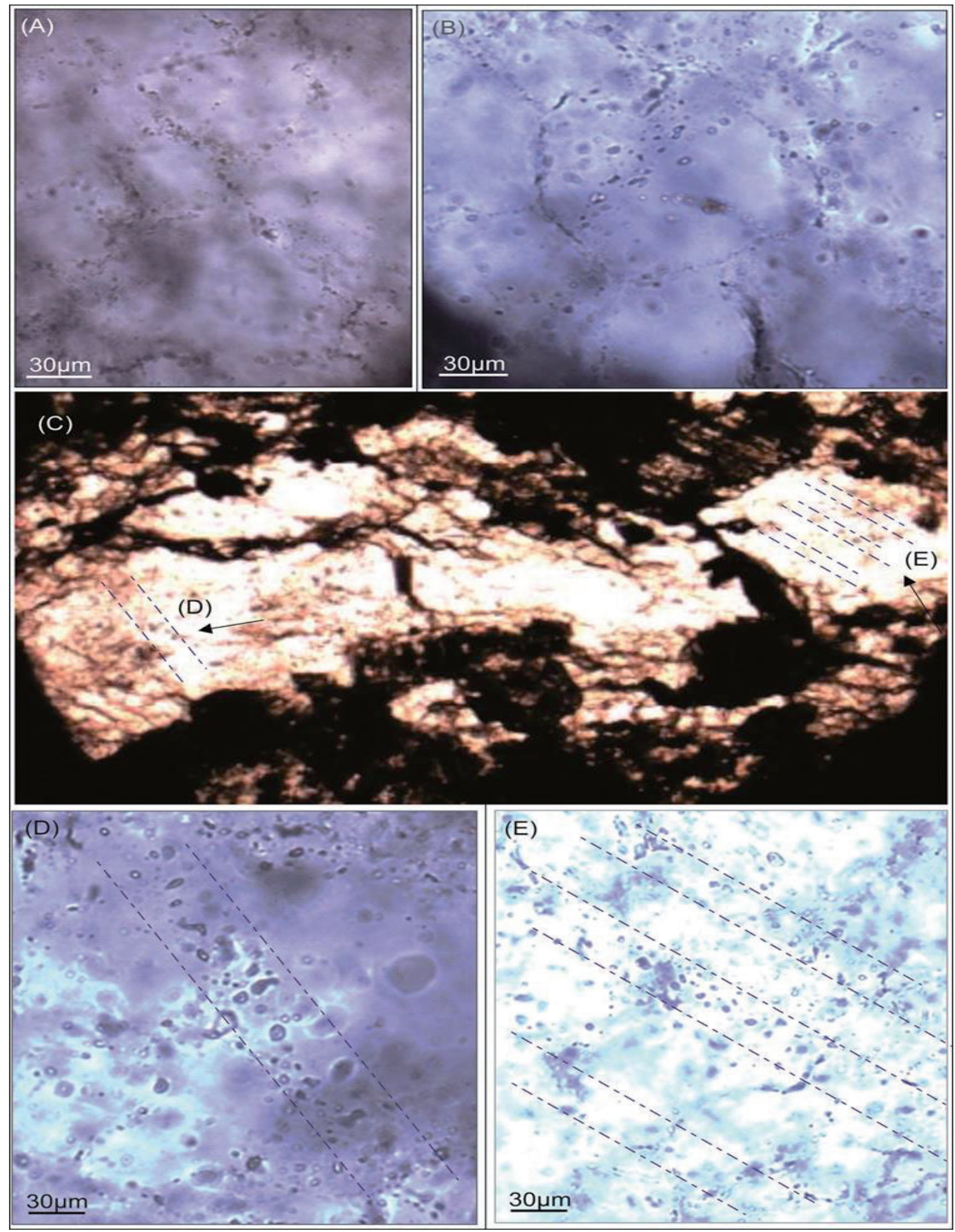

Figura 4. Padrões de distribuição das inclusões fluidas do quartzo do granito foliado. A e B) Inclusões aquosas monofásicas marcando o contorno de subgrãos de quartzo; C) Grão de quartzo recristalizado com a localização das inclusões apresentadas em D e E; D e E) Inclusões dispostas aleatoriamente ou com tendências lineares (indicadas pelas linhas tracejadas), sem nunca traspassar os limites do grão.

Figure 4. Distribution patterns of the fluid inclusions from the foliated granite quartz. A and B) Aqueous single-phases inclusions circularly arranged along quartz subgrains; $C$ ) Recrystallized quartz grain showing the location from D and E inclusions; $D$ and E) Inclusions randomly arranged or with linear tendency (between dotted lines), never transpassing the grain edges. 


\subsubsection{Quartzo do filonito}

Nos cristais neoformados de quartzo foi encontrado o maior número de inclusões, o que pode indicar um fluxo de fluido maior durante sua formação, ou que a menor deformação deste tipo de quartzo permitiu a maior conservação das inclusões.

As inclusões fluidas analisadas na microtermometria apresentam tamanhos entre 7 e $25 \mu \mathrm{m}$, são claras, aquosas, bifásicas ( $\mathrm{L}+\mathrm{V})$, sem indícios da presença de $\mathrm{CO}_{2}$. As inclusões analisadas ocorrem ou não associadas com inclusões monofásicas aquosas e, mais raramente, com inclusões esvaziadas, com características de estrangulamento. A distribuição das inclusões analisadas ocorre das seguintes formas, sem exceder os limites dos cristais de quartzo: inclusões alinhadas paralelamente com o que parecem ser as faces de crescimento do cristal de quartzo (Fig. 5A e B); inclusões bifásicas isoladas (geralmente as de maior tamanho) (Fig. $5 \mathrm{C}$ e F); inclusões dispersas aleatoriamente no interior do cristal (Fig. 5D e E); inclusões dispostas com tendência linear (Fig. 5G e H), ou ainda inclusões monofásicas dispostas circularmente no que aparentam ser contornos de subgrãos dentro do cristal de quartzo (Fig. 5I).

0 volume de preenchimento de gás das inclusões foi calculado entre 6 e 16\%, com um único valor discrepante de $20 \%$. As formas das inclusões variam entre anedrais alongadas, arredondadas, ou mais raramente subedrais a euedrais

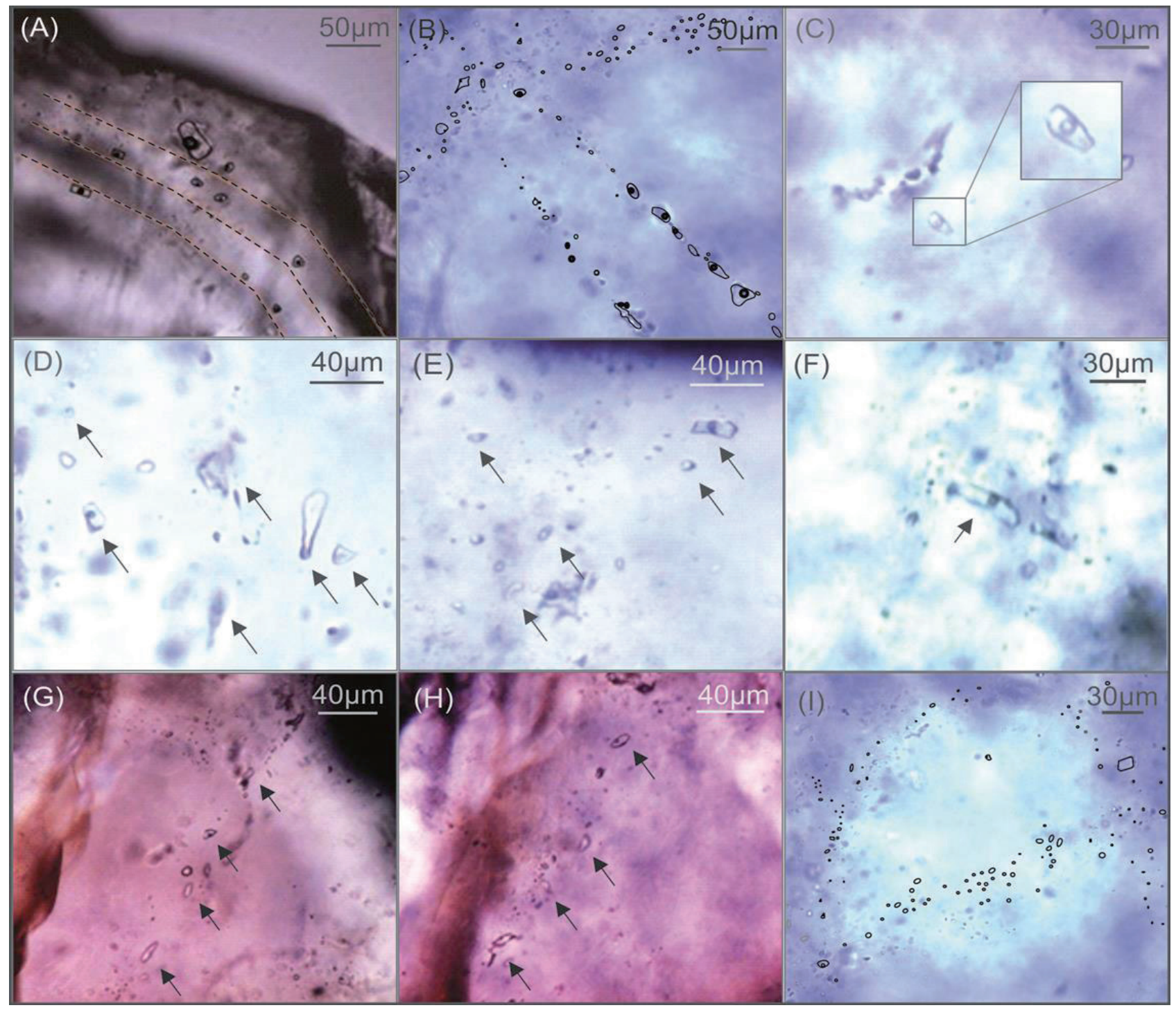

Figura 5. Padrões de distribuição das inclusões fluidas do quartzo do filonito, bifásicas e monofásicas, de origem primária. A e B) Inclusões distribuídas ao longo do que aparentam ser linhas de crescimento do quartzo; C e F) Inclusões bifásicas isoladas; D e E) Inclusões distribuídas aleatoriamente (setas); G e H) Inclusões dispostas com tendência linear intragranular; I) Inclusões monofásicas dispostas circularmente.

Figure 5. Distribution pattern from fluid inclusions of the quartz from phyllonite, two-phase and single-phase, primary in origin. A and B) Inclusions distributed along what appears to be quartz growth lines; $C$ and F) Isolated two-phase inclusions; D and E) Randomly distributed inclusions (arrows); G and H) Inclusions arranged with intra granular linear tendency; I) Single-phase inclusions circularly arranged. 
retangulares. As propriedades das inclusões são semelhantes o suficiente para serem consideradas pertencentes a uma mesma geração de inclusões fluidas. As inclusões fluidas analisadas no quartzo do filonito podem ser consideradas de origem primária, devido à distribuição intracristalina das inclusões fluidas.

\subsubsection{Quartzo do veio}

As inclusões fluidas do quartzo do veio analisadas na microtermometria possuem tamanhos de até $15 \mu \mathrm{m}$, cor clara, são aquosas e bifásicas $(\mathrm{L}+\mathrm{V})$, sem indícios da presença de $\mathrm{CO}_{2}$. As inclusões fluidas analisadas possuem formas regulares, geralmente alongadas ou arredondadas, estando em geral associadas com inclusões monofásicas aquosas. 0 volume de preenchimento de gás nas inclusões oscila entre 6 e $20 \%$, sendo mais representativos valores próximos a $10 \%$.

As inclusões fluidas analisadas nos cristais de quartzo do veio, apesar de possuírem características muito similares, podem ser agrupadas em duas associações de inclusões fluidas, de acordo com sua forma de distribuição. A associação 1 é composta por inclusões fluidas distribuidas aleatóriamente no interior do cristal de quartzo (Fig. $6 \mathrm{~A} \mathrm{e}$ B), sendo consideradas de origem primária. Já as inclusões fluidas da associação 2 estão dispostas em trilhas intragranulares bem definidas (Fig. 6A e B), caracterizando inclusões de origem pseudosecundária.

\subsection{Microtermometria das inclusões fluidas}

\subsubsection{Quartzo do granito foliado}

No granito foliado foram realizadas 13 medidas de aquecimento e 16 medidas de fusão do gelo. Os valores de temperatura de homogeneização $\left(\mathrm{T}_{\mathrm{h}}\right)$ para a fase líquida variaram entre $150^{\circ} \mathrm{C}$ e $250^{\circ} \mathrm{C}$. No histograma de frequência das temperaturas de homogeneização (Fig. 8B), o intervalo obtido entre $190^{\circ} \mathrm{C}$ e $220^{\circ} \mathrm{C}$ foi considerado mais confiável estatisticamente, pois apresenta distribuição normal (assimétrica negativa). A $\mathrm{T}_{\mathrm{h}}$ média referente a este intervalo é de $205^{\circ} \mathrm{C}$. Os valores

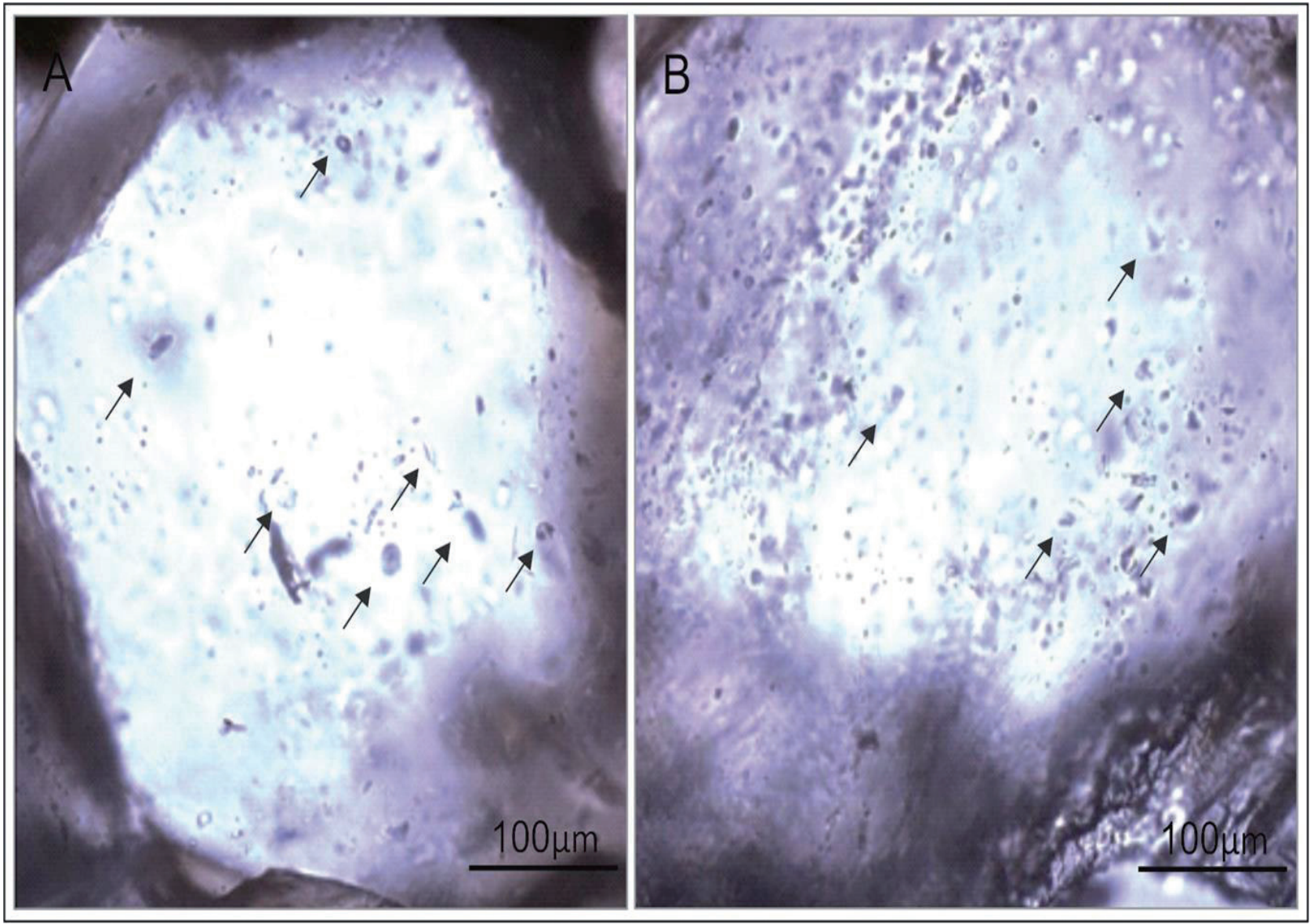

Figura 6. Distribuição característica das inclusões fluidas da associação 1 no quartzo do veio. A e B) distribuição aleatória, dentro do interior de um cristal de quartzo, de inclusões primárias, bifásicas e monofásicas aquosas (algumas inclusões são indicadas pelas setas). Figure 6. Typical distribution of fluid inclusions from the association 1 in the quartz of the vein. A and B) Random distribution inside a quartz crystal of aqueous two-phase and single-phase primary inclusions (some of them are indicated by arrows). 


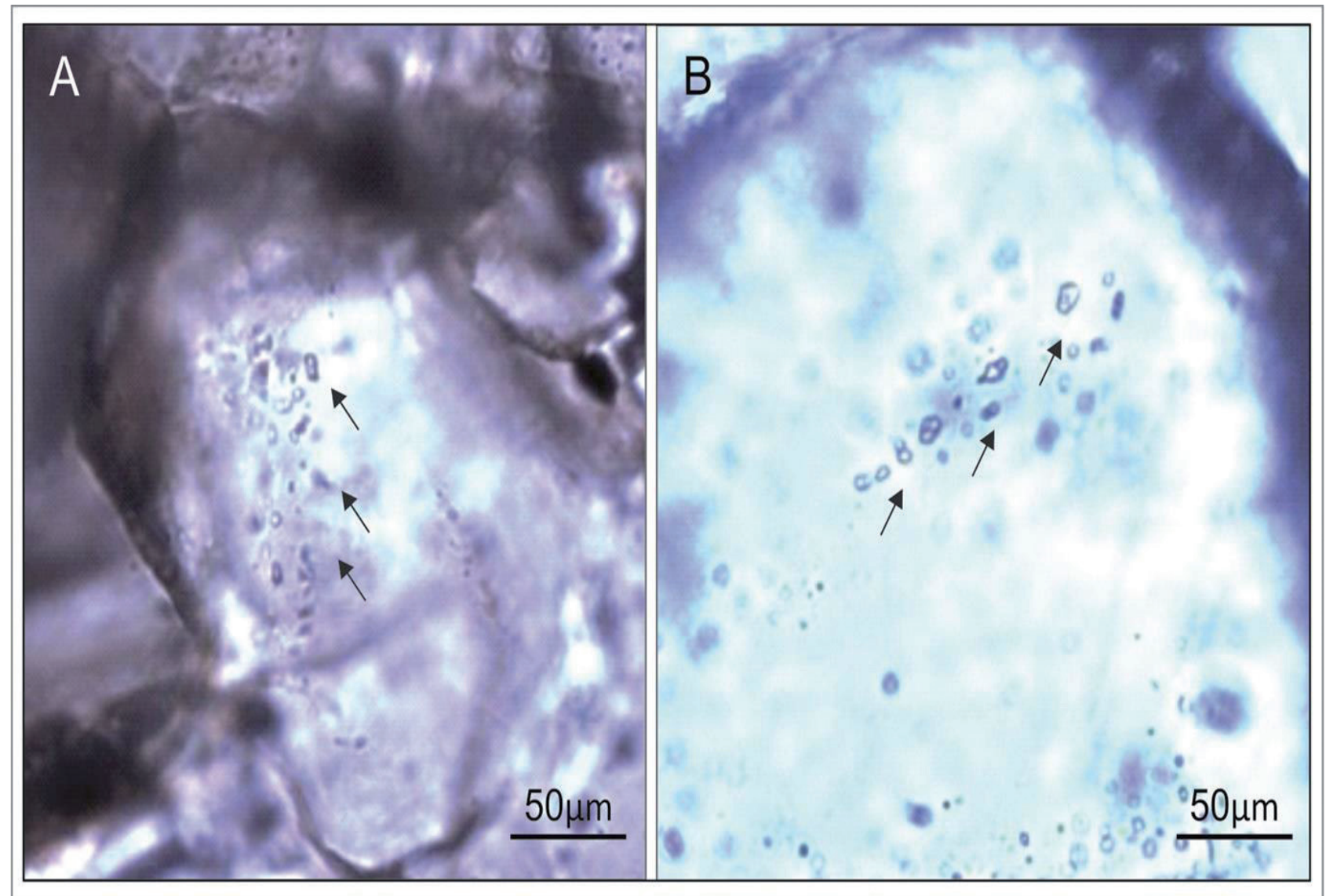

Figura 7. Distribuição característica das inclusões fluidas da associação 2 do quartzo do veio. A e B) distribuição disposta ao longo de trilha intragranular (indicada pelas setas) de inclusões bifásicas e monofásicas pseudosecundárias.

Figure 7. Typical distribution of fluid inclusions from the association 2 in the quartz of the vein. A and B) Distribution arranged along short trails (indicated by arrows) of aqueous two-phase and single-phase pseudosecondary inclusions.

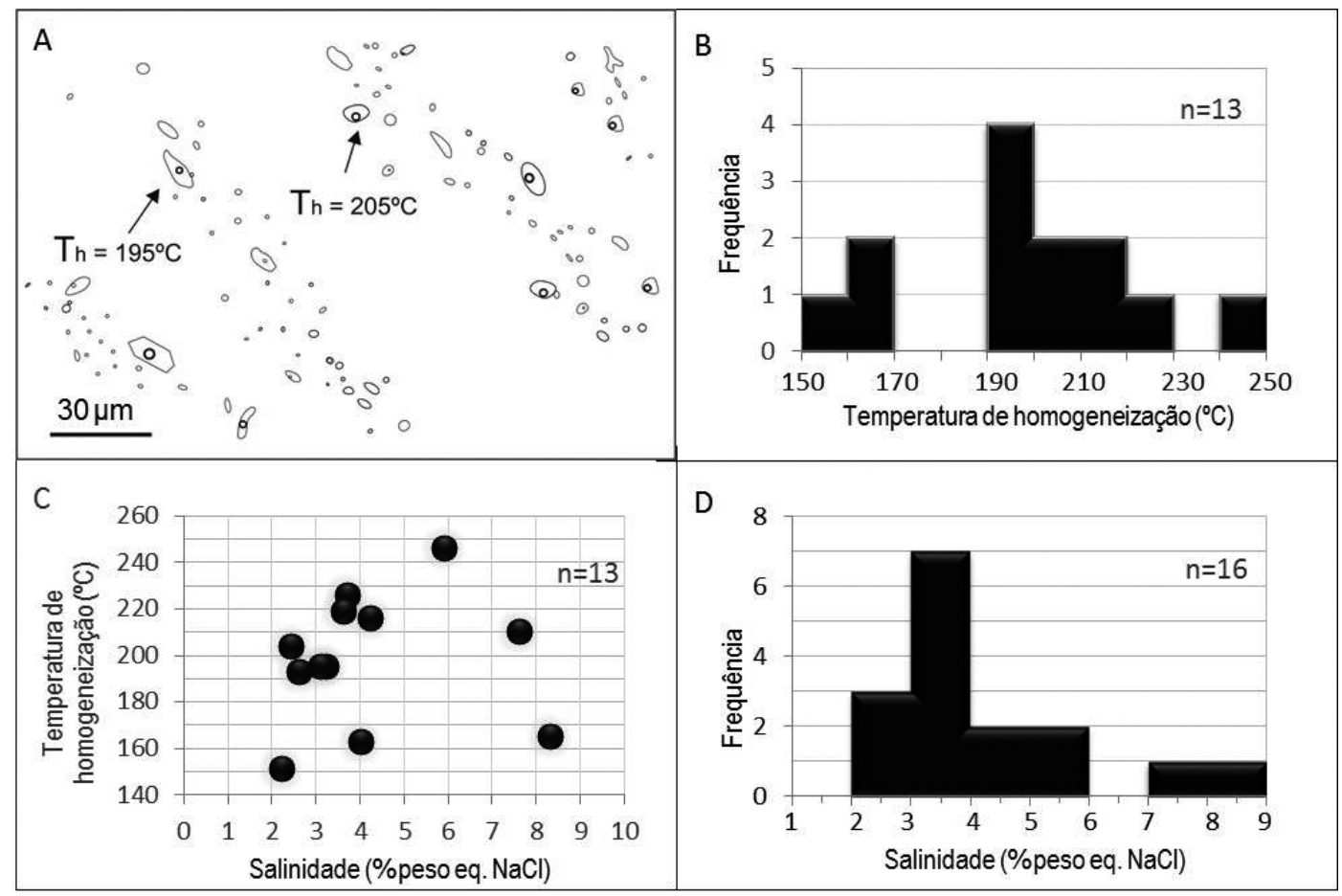

Figura 8. Análises microtermométricas em quartzo do granito foliado. A) Desenho esquemático mostrando a distribuição das inclusões fluidas. As setas indicam as inclusões bifásicas; B) Histograma de frequência das temperaturas de homogeneização $\left({ }^{\circ} \mathrm{C}\right)$; C) Distribuição das inclusões fluidas analisadas em diagrama $\mathrm{T}_{\mathrm{h}}\left({ }^{\circ} \mathrm{C}\right) \times$ x salinidade (\% peso eq. NaCl); D) Histograma de frequência das salinidades (\% peso eq. $\mathrm{NaCl}$ ).

Figure 8. Microtermometric analysis in the quartz from the foliated granite. A) Schematic drawing showing the distribution of fluid inclusions; B) Frequency histogram for homogenization temperatures $\left({ }^{\circ} \mathrm{C}\right)$; $C$ ) Distribution of the analyzed fluid inclusions in $T_{h}$ $\left({ }^{\circ} \mathrm{C}\right)$ x salinity (\% eq. weight of $\mathrm{NaCl}$ ) diagram; D) Frequency histogram for salinities (\% eq. weight of $\left.\mathrm{NaCl}\right)$. 


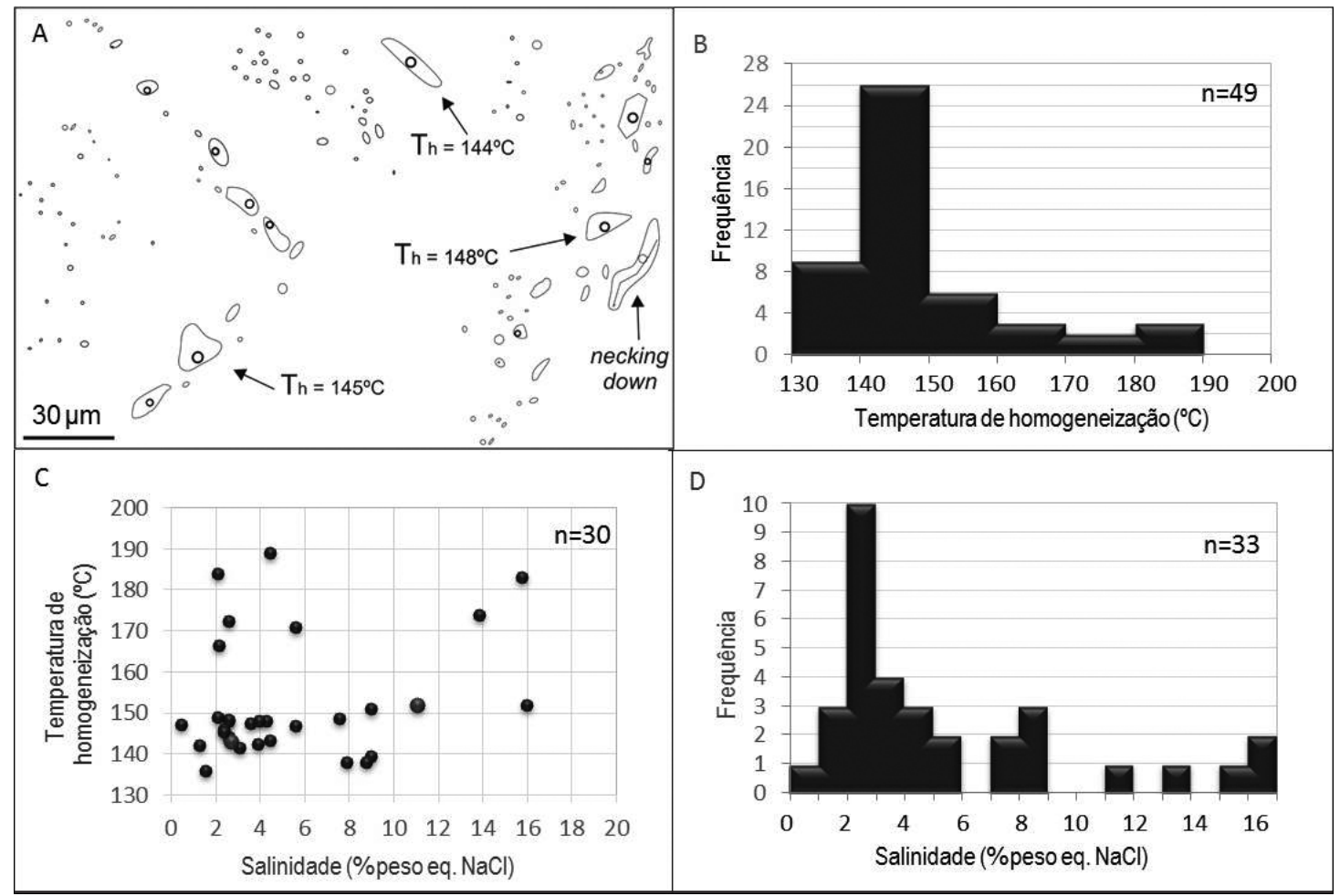

Figura 9. Análises microtermométricas em quartzo do filonito. A) Desenho esquemático mostrando a distribuição das inclusões fluidas; B) Histograma de frequência das temperaturas de homogeneização $\left({ }^{\circ} \mathrm{C}\right)$; C) Distribuição das inclusões fluidas analisadas em diagrama $\mathrm{T}_{\mathrm{h}}\left({ }^{\circ} \mathrm{C}\right) \mathrm{x}$ salinidade (\% peso eq. $\mathrm{NaCl}$ ); D) Histograma de frequência das salinidades (\% peso eq. $\mathrm{NaCl}$ ). Figure 9. Microtermometric analysis in the quartz from the phyllonite. A) Schematic drawing showing the distribution of fluid inclusions; B) Frequency histogram for homogenization temperatures $\left.\left({ }^{\circ} \mathrm{C}\right) ; C\right)$ Distribution of the analyzed fluid inclusions in $T_{h}\left({ }^{\circ} C\right)$ $x$ salinity (\% eq. weight of $\mathrm{NaCl}$ ) diagram; D) Frequency histogram for salinities (\% eq. Weight of NaCl).

de temperaturas de fusão do gelo $\left(\mathrm{T}_{\mathrm{fg}}\right)$ são equivalentes a salinidades baixas, entre $2 \%$ e $6 \%$ peso eq. $\mathrm{NaCl}$ (Fig. 8D), sendo considerada uma média representativa da salinidade para estas inclusões de $3 \%$ peso eq. $\mathrm{NaCl}$.

0 espalhamento nos valores obtidos de $T_{h}$ e $\mathrm{T}_{\mathrm{fg}}$ (Fig. 8C) pode ser explicado por alterações pós-formacionais em inclusões analisadas, como por exemplo, vazamentos, variação do conteúdo do volume de gás e/ou comportamento metaestável de algumas inclusões. A figura 8A apresenta um desenho esquemático da distribuição das inclusões fluidas do quartzo do granito foliado.

\subsubsection{Quartzo do filonito}

Foram realizadas 49 medidas de aquecimento e 33 medidas de fusão do gelo. 0 intervalo de temperatura de homogeneização $\left(\mathrm{T}_{h}\right)$ para a fase líquida, atendido pela distribuição normal representada no histograma de frequência para $\mathrm{T}_{h}$ (Fig. 9B), compreende os valores entre $130^{\circ} \mathrm{C}$ e $160^{\circ} \mathrm{C}$, com média de $145^{\circ} \mathrm{C}$. Valores de $\mathrm{T}_{\mathrm{h}}$ entre $170-190^{\circ} \mathrm{C}$ podem ser decorrentes de estrangulamento (Fig. 9C). A salinidade variou desde valores muito baixos até valores intermediários, de 0,5 até $\sim 16 \%$ peso eq. $\mathrm{NaCl}$ (Fig. 9D). A maior concentração de salinidade ocorre na faixa entre 1 e $6 \%$ peso eq. $\mathrm{NaCl}$, sendo a média de salinidade mais representativa para as inclusões do quartzo do filonito de $3 \%$ peso eq. $\mathrm{NaCl}$. A figura 9A apresenta um desenho ilustrativo mostrando a distribuição das inclusões fluidas do quartzo do filonito.

\subsubsection{Quartzo do veio}

No quartzo do veio que corta o granito foliado foram realizadas 39 medidas de aquecimento e 38 medidas de fusão do gelo. A distribuição dos dados em histogramas de frequência indica que estes grupos pertencem a duas gerações de inclusões, as associações 1 e 2 , conforme discutido na petrografia das inclusões fluidas do quartzo do veio.

A associação 1 apresenta valores de temperatura de homogeneização $\left(\mathrm{T}_{\mathrm{h}}\right)$ para a fase líquida entre $180^{\circ} \mathrm{C}$ e $300^{\circ} \mathrm{C}$, com distribuição normal entre $220^{\circ} \mathrm{C}$ e $260^{\circ} \mathrm{C}$ (Fig. 10B). A $\mathrm{T}_{\mathrm{h}}$ média referente ao intervalo de distribuição normal é de $240^{\circ} \mathrm{C}$. As temperaturas de fusão do gelo para este grupo equivalem a salinidades baixas, com valores entre $1 \%$ e $6 \%$ peso eq. $\mathrm{NaCl}$ (Fig. 10D).

A associação 2 apresentou temperaturas de homogeneização $\left(\mathrm{T}_{\mathrm{h}}\right)$ para a fase líquida mais baixas, entre $140^{\circ} \mathrm{C}$ e $220^{\circ} \mathrm{C}$, com distribuição normal 
assimétrica positiva entre os valores de $150^{\circ} \mathrm{C}$ e $190^{\circ} \mathrm{C}$ (Fig. 10B). 0 valor médio de $\mathrm{T}_{\mathrm{h}}$ para o intervalo com distribuição normal é de $170^{\circ} \mathrm{C}$. A salinidade, adquirida através da temperatura de fusão do gelo, variou no mesmo intervalo da associação 1 , entre $1 \%$ e $6 \%$ peso eq. $\mathrm{NaCl}$ (Fig. 10D).

Para ambas as associações (1 e 2) foi considerada uma média representativa da salinidade de $3 \%$ peso eq. $\mathrm{NaCl}$. A figura 10C mostra a variação vertical nos valores de $T_{h}$ para as inclusões fluidas das duas associações. Um desenho esquemático da distribuição das duas associações de inclusões fluidas é apresentado na figura $10 \mathrm{~A}$.

\subsection{Isócoras}

Foram construídos quatro pares de isócoras a partir das médias de densidade e de $\mathrm{T}_{\mathrm{h}}$ das famílias de inclusões fluidas nos cristais de quartzo analisados (Fig. 11). A densidade está diretamente relacionada à salinidade, tendo sido considerados os valores de salinidade média de $3 \%$ peso eq. $\mathrm{NaCl}$, equivalente a densidade de $1,0281 \mathrm{~g} / \mathrm{cm}^{3}$ (Brown, 1989; Bodnar, 2003) para as inclusões fluidas do granito foliado, do filonito e do veio de quartzo.

Para corrigir a pressão mínima de aprisionamento, determinando um ponto da isócora próximo da realidade (ou seja, um par P-T geologicamente coerente e de acordo com o contexto da zona de cisalhamento) foram utilizados indicadores de temperatura (geotermômetros) independentes, baseados nos dados petrográficos e microestruturais.

Para correção da pressão das inclusões do quartzo no granito foliado foi considerado uma $\mathrm{T}=570^{\circ} \mathrm{C}$. Considerou-se como critérios o metamorfismo regional no Complexo Metamórfico Brusque de fácies xisto verde na zona da biotita, com temperaturas máximas estimadas em $570^{\circ} \mathrm{C}$ (Basei et al., 2011a), e a presença de estruturas representativas de temperaturas próximas a $500^{\circ} \mathrm{C}$, como recristalização nas bordas de K-feldspato e ribbons de quartzo (Fig. 3B e C) (Blenkinsop, 2000; Passchier \& Trouw, 2005).

Para correção da pressão do quartzo no filonito foi estabelecida uma $\mathrm{T}=350^{\circ} \mathrm{C}$, considerando que os cristais de quartzo neoformados do filonito são pouco deformados, apresentam extinção ondulante e recristalização incipiente (Fig. 3D e E) (Blenkinsop, 2000; Passchier \& Trouw, 2005). E finalmente, para a isócora do quartzo do veio, foi estabelecida uma $\mathrm{T}<300^{\circ} \mathrm{C}$, pela ausência de feições de deformação significativas, apenas leve extinção ondulante (Fig. 3F) (Blenkinsop, 2000; Passchier \& Trouw, 2005).

Considerando estes geotermômetros, as pressões de aprisionamento corrigidas variam entre 6,5 kbar a 5,4 kbar (média de $\sim 6$ kbar) para o quartzo do granito foliado, $\mathrm{P}$ de 4,6 kbar a 3,6 kbar (média de $\sim 4$ kbar) para o quartzo do filonito e pressões inferiores a $3 \mathrm{kbar}$ para o quartzo do veio (Fig. 11). A pressão de 6,5 kbar corresponde à temperatura de $570^{\circ} \mathrm{C}$, consistente com

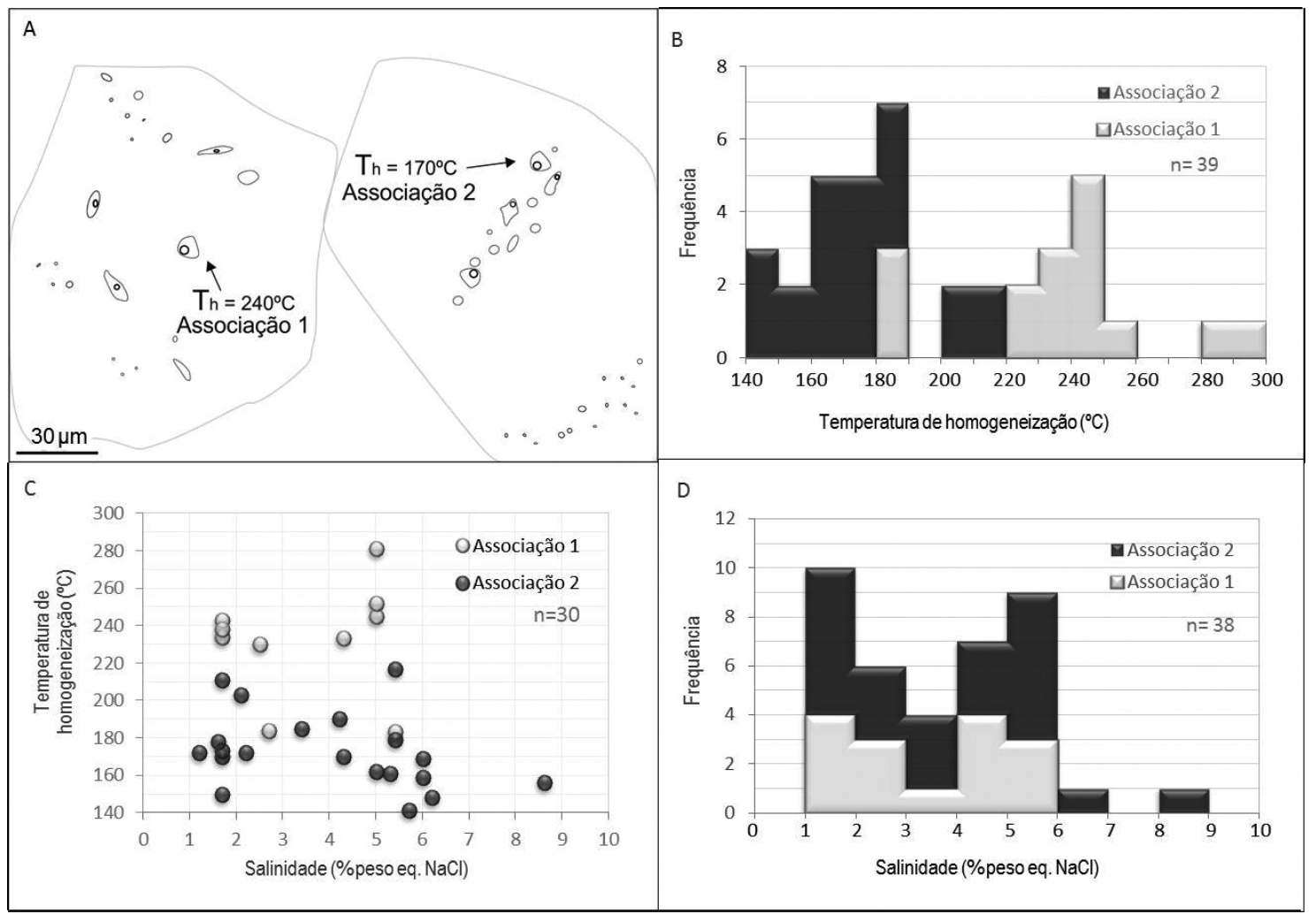

Figura 10. Análises microtermométricas no quartzo do veio. A) Desenho esquemático mostrando a distribuição das associações 1 e 2; B) Histograma de frequência das temperaturas de homogeneização $\left.\left({ }^{\circ} \mathrm{C}\right) ; \mathrm{C}\right)$ Distribuição das inclusões fluidas em diagrama $\mathrm{T}_{\mathrm{h}}\left({ }^{\circ} \mathrm{C}\right) \times \mathrm{xalinida-}$ de (\% peso eq. $\mathrm{NaCl}$ ); D) Histograma de frequências das salinidades (\% peso eq. $\mathrm{NaCl}$ ).

Figure 10. Microtermometric analysis in the quartz from the vein. A) Schematic drawing showing the distribution of fluid inclusions from both associations 1 and 2; B) Frequency histogram for homogenization temperatures $\left.\left({ }^{\circ} \mathrm{C}\right) ; \mathrm{C}\right)$ Distribution of the fluid inclusions in $T_{h}\left({ }^{\circ} \mathrm{C}\right) \mathrm{x}$ salinity (\% eq. weight of $\mathrm{NaCl}$ ) diagram; D) Frequency histogram for salinities (\% eq. weight of $\mathrm{NaCl}$ ). 


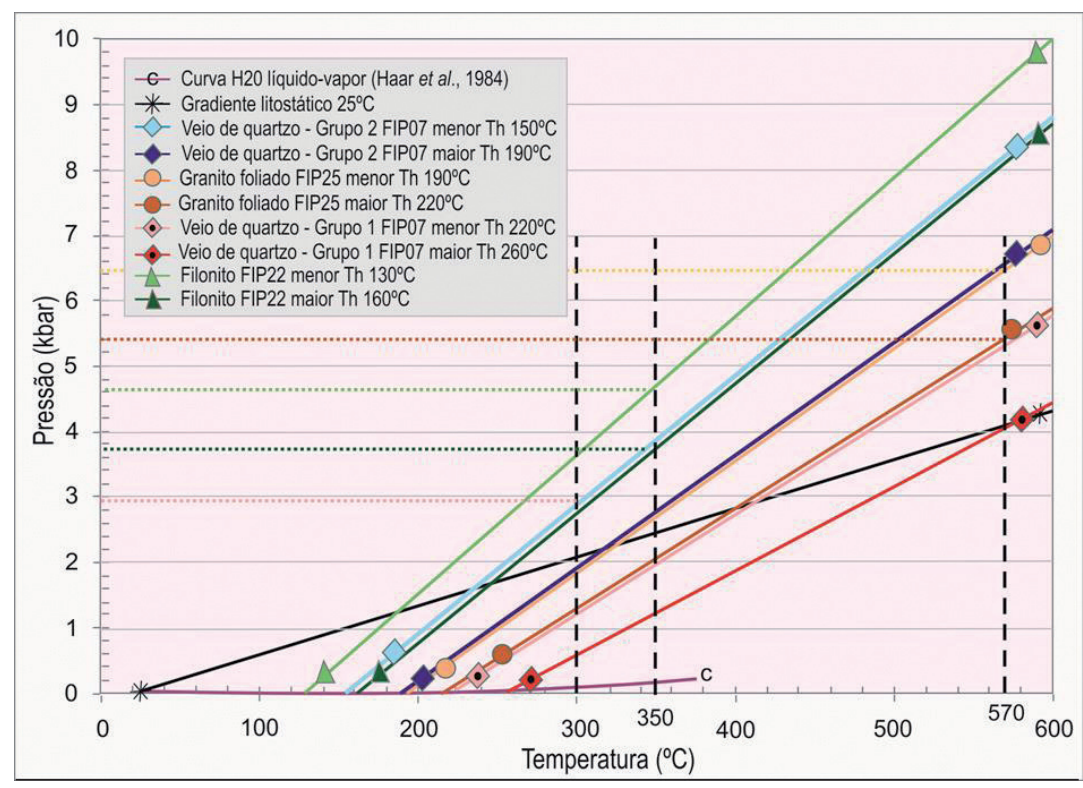

Figura 11. Isócoras obtidas para as inclusões fluidas aquosas em grãos de quartzo de rochas do Granito Parapente, de acordo com a densidade e temperaturas de homogeneização máximas e mínimas das inclusões fluidas de cada amostra e geotermômetros independentes.

Figure 11. Obtained isochores for aqueous fluid inclusions in the Parapente granite quartz grains, according to the density and maximum and minimum homogenization temperatures of each sample and independent geothermometers.

um gradiente geotérmico de $25^{\circ} \mathrm{C} / \mathrm{km}$.

As profundidades de formação das inclusões fluidas obtidas para um gradiente geotérmico de $25^{\circ} \mathrm{C} / \mathrm{km}$ é de $22,8 \mathrm{~km}$ para o quartzo do granito foliado, $14 \mathrm{~km}$ para o quartzo do filonito, e profundidades inferiores a $12 \mathrm{~km}$ para o quartzo do veio. As relações destas profundidades com as zonas crustais de formação de rochas de falha podem ser visualizadas na figura 12 .

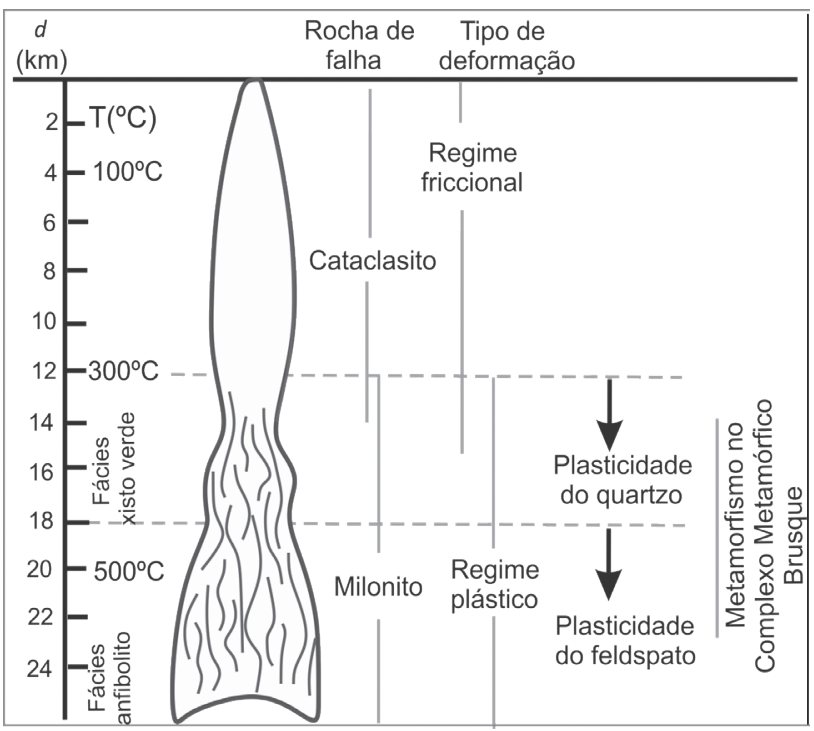

Figura 12. Relação entre temperatura, regimes de deformação, metamorfismo e rochas de falha com base em uma geoterma de $25^{\circ} \mathrm{C} / \mathrm{km}$ (segundo Scholz, 1988).

Figure 12. Relathionship between temperature, deformation regimes, metamorphism and fault rocks based in a $25^{\circ} \mathrm{C} / \mathrm{km}$ geotherm (after Scholz, 1988).

\section{Discussão e conclusões}

\subsection{Características dos fluidos e fontes}

Não está claro se os fluidos encontrados em grãos de quartzo do granito foliado, filonito e veio tiveram origem em uma ou mais fontes, embora as inclusões do granito foliado sejam muito similares, em termos de $T_{h}$, salinidade e morfologia, às do veio de quartzo (Fig. 13).

Não foram encontradas evidencias suficientes para explicar o porquê das $\mathrm{T}_{\mathrm{h}}$ das inclusões da associação 1 do veio $\left(220-240^{\circ} \mathrm{C}\right)$ serem razoavelmente maiores que as do granito foliado (190$220^{\circ} \mathrm{C}$ ) (Fig. 13). Uma das possibilidades seria a percolação de um outro fluido hidrotermal, mais quente que a rocha encaixante, possibilitada pelas fraturas que originaram o veio. As inclusões fluidas da associação 2 do veio $\left(\mathrm{T}_{\mathrm{h}}=150-190^{\circ} \mathrm{C}\right)$, com salinidade e morfologia muito semelhantes às da associação 1, provavelmente correspondem a um estágio tardio de aprisionamento do mesmo fluido da associação 1 em microfraturas seladas (inclusões fluidas pseudosecundárias), ligadas a um episódio posterior de reequilíbrio do quartzo do veio.

Nas inclusões fluidas do quartzo do filonito, a $\mathrm{T}_{\mathrm{h}}$ média de $145^{\circ} \mathrm{C}$ é significativamente mais baixa que as do granito foliado e do veio. Além disso, nestas inclusões, as concentrações equivalentes em peso de $\mathrm{NaCl}$ chegam em níveis intermediários, em contraste com as concentrações baixas do granito foliado e do veio, e apresentam um trend de 
diluição (Fig. 13), possivelmente decorrente da incorporação de água meteórica e/ou outros fluidos canalizados pela zona de falha.

As duas fontes principais de fluidos hidrotermais aquosos em zonas de cisalhamento são os fluidos aquosos magmáticos derivados da cristalização de corpos granitoides que ocorrem nas cir- cunvizinhanças e os fluidos intersticiais expulsos de camadas sedimentares devido à compactação causada por esforços tectônicos ou reações metamórficas (Roedder, 1984; Bodnar, 1992). A fonte hidrotermal de maior relevância no contexto geológico da ZCIP provavelmente está ligada ao metamorfismo no Complexo Metamórfico Brusque.

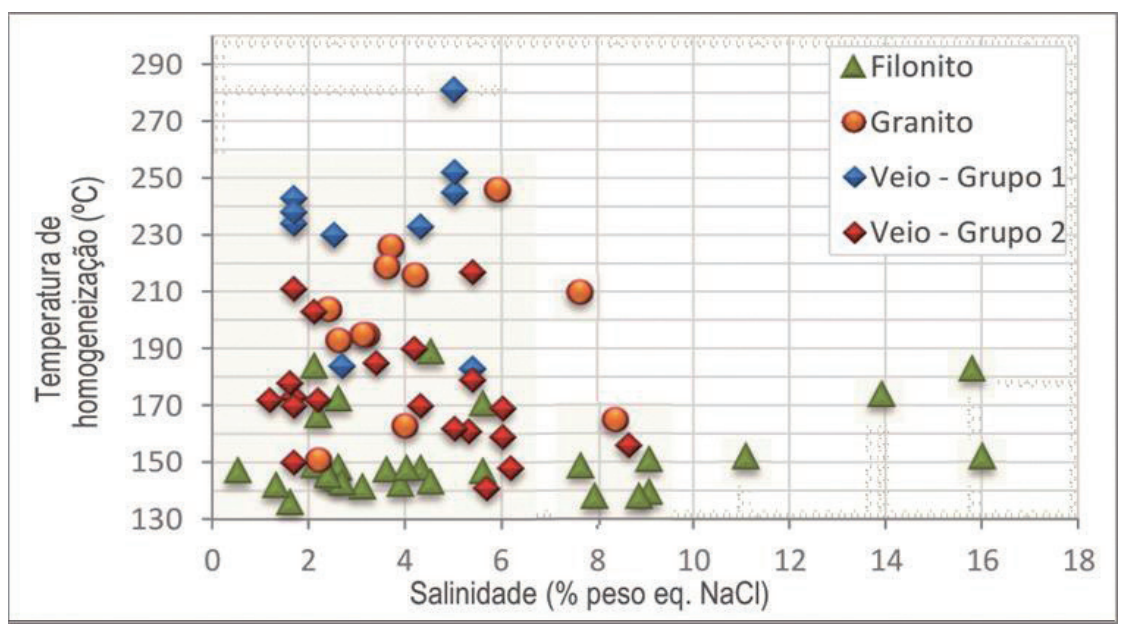

Figura 13. Distribuição das inclusões fluidas analisadas em quartzo do granito foliado, filonito e veio em diagrama $\mathrm{T}_{\mathrm{h}}(\underline{\circ} \mathrm{C}) \mathrm{x}$ salinidade (\% peso eq. $\mathrm{NaCl}$ ).

Figure 13. Distribution from analyzed fluid inclusions in quartz from foliated granite, phyllonite and vein in $T_{h}\left({ }^{\circ} \mathrm{C}\right) \times$ salinity $(\%$ eq. weight of $\mathrm{NaCl}$ ) diagram.

\subsection{Evolução da Zona de Cisalhamento Itajaí-Perim- bó}

As evidências obtidas na análise petrográfica e no estudo de inclusões fluidas, juntamente com dados disponíveis na bibliografia, permitem estabelecer a seguinte evolução para a ZCIP.

A colocação do Granito Parapente, há aproximadamente 843 Ma (Basei et al., 2008) se deu em uma profundidade mínima de $23 \mathrm{~km}$. As microestruturas indicam que a deformação do Granito Parapente é frágil-dúctil de baixa a média temperatura, e atestam que o granito é pré-tectônico em relação ao evento que originou a ZCIP.

As condições de $\mathrm{P}$ e T estimadas para a deformação do Granito Parapente são compatíveis com as condições de metamorfismo do Complexo Metamórfico Brusque, entre 640-600 Ma (Basei et al., 2011a). A ZCIP deve ter sua origem neste período, com características de cavalgamento.

Após a deposição da Bacia do Itajaí, em torno de 549 Ma (Guadagnin et al., 2010), formam-se as mineralizações de Ribeirão da Prata, com geometria marcada pelo caráter transcorrente da ZCIP, possivelmente por volta de $532 \mathrm{Ma}$ (Rocha et al., 2005).

A movimentação transcorrente da zona de cisalhamento também está evidenciada nos filonitos do Granito Parapente os quais, juntamente com as mineralizações de Ribeirão da Prata, atestam um intenso transporte de fluidos pela ZCIP. As salinidades baixas, típicas de fluidos tardios de baixa temperatura, sugerem que a zona de cisalhamento canalizou fluidos expulsos de sedimentos e rochas hidratadas.

Pode-se estimar que a ZCIP esteve ativa como cavalgamento em níveis crustais intermediários $(\sim 23-14 \mathrm{~km})$, com um deslocamento vertical de pelo menos $10 \mathrm{~km}$ antes de começar a funcionar com movimentação lateral-direita. Em profundidades mais rasas, inferiores a $12 \mathrm{~km}$, a zona de falha pode ter sido responsável pela formação de fraturas nos domínios do Granito Parapente. 0 registro mais recente da movimentação transcorrente da ZCIP é há 250 Ma (Rostirolla et al., 2003), em rochas da Bacia do Paraná.

Agradecimentos: Agradecemos a Régis M. K. Borges e a um revisor anônimo pelas correções e sugestões que permitiram aprimorar este trabalho. Este texto resulta do Trabalho de Conclusão de Curso de I. W. Hadlich, desenvolvido no Departamento de Geociências da UFSC com apoio do Programa Petrobrás de Formação de Recursos Humanos - PFRH 240. FJA é bolsista CAPES, Brasil.

\section{Referências}

Basei, M.A.S., Nutman, A., Grasso, C.B., Vlach, S., Siga Jr., O. \& Osako, L. 2008. The cryogenian rift-related granitogenesis of the Dom Feliciano belt, Southern 
Brazil. In: INTERNATIONAL SHRIMP WORKSHOP, 4, 2008, Saint-Petersburg. Abstract Volume, 24-26.

Basei, M.A.S., Campos Neto, M.C., Castro, N.A., Nutman, A.P., Wemmer, K., Yamamoto, M.T., Hueck, M., Osako, L., Siga Jr., O. \& Passarelli, C.R. 2011a. Tectonic evolution of the Brusque Group, Dom Feliciano belt, Santa Catarina, Southern Brazil. Earth Science Research Journal, 32(1): 324-350.

Basei, M.A.S., Drukas, C.O., Nutman, A.P., Wemmer, K., Dunyi, L., Santos, P.R., Passarelli, C.R., Campos Neto, M.C., Siga Jr., O. \& Osako, L. 2011b. The Itajaí foreland basin: a tectono-sedimentary record of the Ediacaran period, Southern Brazil. Earth Science Research Journal, 100(1): 543-569.

Biondi, J.C., Schicker, G. \& Bugalho, A. 1992. Processos mineralizadores em bacias tardi-orogênicas: 1 - Influência das estruturas rígidas na geração dos depósitos da Minepar e do Ribeirão da Prata, Grupo Itajaí (SC). Revista Brasileira de Geociencias, 22(1): 275-288.

Blenkinsop, T. 2000. Deformation microstructures and mechanisms in minerals and rocks. Dordrecht: Kluwer, $150 \mathrm{p}$.

Bodnar, R.J. 1992. Can we recognize magmatic fluid inclusions in fossil systems based on room-temperature phase relations and microthermometric behavior? In: Hedenquist, J.W. (Ed.). Magmatic contributions to hydrothermal systems. Geological Survey of Japan, Report n‥ 279, 26-30.

Bodnar, R.J. 2003. Introduction to aqueous-electrolyte fluid inclusions. In: Samson, I., Anderson, A. \& Marshall, D. (eds.). Fluid inclusions: analysis and interpratation. Vancouver, Mineralogical Association of Canada Short Course Series, 32: 81-100.

Boullier, A.M. 1999. Fluid inclusions: tectonic indicators. Journal of Structural Geology, 21(1): 1229-1235.

Brito Neves, B.B. \& Fuck, R.A. 2013. Neoproterozoic evolution of the basement of the South-American platform. Journal of South American Earth Sciences, 47: 72-89.

Brown, P.E. 1989. FLINCOR: a microcomputer program for the reduction and investigation of fluid inclusion data. American Mineralogist, 74(1): 1390-1393.

Caldasso, A.L.S., Krebs, A.S.J., Silva, M.A.S., Camozzato, E. \& Ramgrab, G.E. 1995. Programa de Levantamentos Geológicos Básicos 1: 100.000; Folha Botuverá (SG-22-Z-D-I-2), SC. CPRM, Brasília.

Chemale Jr., F. 2007. Tectonic evolution of Neoproterozoic to Eopaleozoic belts in the Southern Brazil and South Africa. In: WORKSHOP PROBLEMS IN THE WESTERN GONDWANA GEOLOGY, 1, 2007, Gramado, RS. Extended Abstracts, 22-25.

Foreman, J.L. \& Dunne, W.M. 1991. Conditions of vein formation in the Southern Appalachian foreland: constrains from vein geometries and fluid inclusions. Journal of Structural Geology, 13(10): 11731183.

Fuzikawa, K. 1985. Inclusões fluidas: métodos usuais de estudo e aplicações. Contribuições à geologia e à petrologia. Belo Horizonte: SBG/MG, 29-44.

Guadagnin, F., Chemale Jr., F., Dussin, I.A., Jelinek, A.R.,
Santos, M.N., Borba, M.L., Justino, D., Bertotti, A.L. \& Alessandretti, L. 2010. Depositional age and provenance of the Itajaí Basin, Santa Catarina State, Brazil: implications for SW Gondwana correlation. Precambrian Research, 180(1): 156-182.

Haar, L., Gallagher, J.S. \& Kell, G.S. 1984. NBS/NRC steam tables: Thermodynamic and transport properties and computer programs for vapor and liquid states of water in SI units. Washington, DC: Hemisphere, 320 p.

Hodgkins, M.A. \& Stewart, K.G. 1994. The use of fluid inclusions to constrain fault zone pressure, temperature and kinematic history: an example from the Alpi Apuane, Italy. Journal of Structural Geology, 16(1): 85-96.

Hollister, L.S. \& Crawford, M.L. 1981. Fluid inclusions: applications to petrology. Mineralogical Association of Canada, Short Course Series, 6: 157-181.

Jefferies, S.P., Holdsworth, R.E., Wibberley, C.A.J.M., Shimamoto, T.M., Spiers, C.J., Niemeijer, A.R. \& Lloyd, G.E. 2006. The nature and importance of phyllonite development in crustal-scale fault cores: an example from the Median Tectonic Line, Japan. Journal of Structural Geology, 28(1): 220-235.

Lacroix, B., Buatier, M., Labaume, P., Travé, A., Dubois, M., Charpentier, D., Ventalon, S. \& Convert-Gaubier, D. 2011. Microtectonic and geochemical characterization of thrusting in a foreland basin: example of the South-Pyrenean orogenic wedge (Spain). Journal of Structural Geology, 33(1): 1359-1377.

Lacroix, B., Travé, A., Buatier, M., Labaume, P., Vennemann, T. \& Dubois, M. 2014. Syntectonic fluid-flow along thrust faults: example of the South-Pyrenean fold-and-thrust belt. Marine Petroleum Geology, 49: 84-98.

Parry, W.T. 1998. Fault-fluid compositions from fluid-inclusion observations and solubilities of fracture-sealing minerals. Tectonophysics, 290(1-2): 1-26.

Parry, W.T. \& Bruhn, R.L. 1987. Fluid inclusion evidence for minimum $11 \mathrm{~km}$ vertical offset on the Wasatch fault, Utah. Geology, 15(1): 67-70.

Passchier, C.W. \& Trouw, R.A. 2005. Microtectonics. Springer: Berlim, 366 p.

Passelègue, F.X., Fabbri, O., Dubois, M. \& Ventalon, S. 2014. Fluid overpressure along an Oligocene outof-sequence thrust in the Shimanto Belt, SW Japan. Journal of Asian Earth Sciences, 86: 12-24.

Philipp, R.P., Mallmann, G., Bitencourt, M.F., Souza, E.R., Souza, M.M.A., Liz, J.D., Wild, F., Arendt, S., Oliveira, A.S., Duarte L., Rivera, C.B. \& Prado, M. 2004. Caracterização litológica e evolução metamórfica da porção leste do Complexo Metamórfico Brusque, Santa Catarina. Revista Brasileira de Geociências, 34(1): 21-34.

Rocha, F.F.N., Bastos Neto, A.C., Remus, M.V.D. \& Pereira, V.P. 2005. A fonte dos metais da Mina de Ouro do Schramm, Santa Catarina: evidências de dados de isótopos de $\mathrm{Pb}$ e elementos terras raras. Pesquisas em Geociências, 32(1): 51-31.

Roedder, E. 1984. Fluid inclusions. Reviews in mineralogy, 12: $646 \mathrm{p}$. 
Ronchi, F.C. 2014. Análise estrutural da Zona de Cisalhamento Itajaí-Perimbó. Florianópolis, 83 p. Monografia de Conclusão de Curso, Curso de Geologia, Departamento de Geociências, Universidade Federal de Santa Catarina.

Ronchi, F.C. \& Althoff, F.J. 2015. Análise estrutural da Zona de Cisalhamento Itajaí-Perimbó. In: SIMPÓSIO SUL-BRASILEIRO DE GEOLOGIA, 9, 2015, Florianópolis. Anais... Florianópolis, SBG, v. 9, p. 163.

Rostirolla, S.P., Soares, P.C. \& Alkmin, F.F. 1992. Análise estrutural da tectônica deformadora da Bacia de Itajaí, Estado de Santa Catarina, Brasil. Boletim de Geociências daPetrobrás, 6 (3-4): 123-147.

Rostirolla, S.P., Ahrendt, A., Soares, P.C. \& Carmignani, L. 1999. Basin analysis and mineral endowment of the Proterozoic Itajaí Basin, south-east Brazil. Basin Research, 11(1): 127-142.

Rostirolla, S.P., Mancini, F., Rigoti, A. \& Kraft, R.P. 2003. Structural styles of the Permian reactivation of the Perimbo Fault Zone, Paraná Basin, Brazil. Journal of South American Earth Sciences, 16 (4): 287-300.

Schmid, S.M. \& Handy, M.R. 1991. Towards a genetic classification of fault rocks: geological usage and tectonophysical implications. In: Mueller, D.W., Mckenzie, J.A. \& Weissert, H. (Eds.). 1991. Controversies in modern geology: evolution of geological theories in sedimentology, Earth history and tectonics. London: Academic Press, 339-361.

Manuscrito 631

Editores: Edinei Koester \& Paulo A. Souza
Scholz, C.H. 1988. The brittle-plastic transition and the depth of seismic faulting. Geologische Rundschau, 77(1): 319-328.

Shepherd, T. 1981. Temperature programmable heating/freezing stage for microthermometric analysis of fluid inclusions. Economic Geology, 76 (1): 12441247.

Silva, L.C. 1991. O Cinturão Metavulcanossedimentar Brusque e a evolução policíclica das faixas dobradas proterozoicas no sul do Brasil: uma revisão. Revista Brasileira de Geociências, 21(1): 60-73.

Szulc, A.G., Alsop, G.I. \& Oliver, G.J.H. 2008. Kinematic and thermal constraints on the reactivation of the Outer Hebrides Fault Zone, NW Scotland. Geological Magazine, 145(5): 623-636.

Trouw, R.A.J., Passchier, C.W. \& Wiersma, D.J. 2010. Atlas of mylonites and related microstrutures. Berlin: Springer-Verlag, $322 \mathrm{p}$.

Van den Kerkhof, A.M. \& Hein, U.F. 2001. Fluid inclusion petrography. Lithos, 55(1): 27-47.

Vrolijk, P.G. 1987. Paleohydrogeology and fluid evolution of the Kodiak accretionary complex, Alaska, 232 p. Ph.D. thesis, University of California, Santa Cruz.

Wildner, W., Camozzato, E., Toniolo, J.A., Binotto, R.B., Iglesias, C.M.F. \& Laux, J.H. 2014. Mapa geológico do Estado de Santa Catarina. Escala: 1:500.000. Programa Geologia do Brasil. Subprograma de Cartografia Geológica Regional. Porto Alegre: CPRM. 